\title{
Association of whole blood copper and preeclampsia: A Cohort study in China
}

\section{Huan Ying Xu ( $\nabla$ 843857263@qq.com )}

Foshan Chancheng Central Hospital https://orcid.org/0000-0002-2815-4322

\section{Ying Chen}

Guangzhou University of Chinese Medicine

\section{Su Zhen Wu}

Foshan Chancheng Centrel Hospital

\section{Qiao Ling Zhu}

Foshan Chancheng Central Hospital

\section{Yu Chen}

Foshan Chancheng Central Hospital

\section{Min Hua Tan}

Foshan Chancheng Central Hospital

\section{Miao Miao Zhang}

Foshan Chancheng Central Hospital

\section{Qi Xin Ou}

Guangzhou University of Chinese Medicine

\section{Research article}

Keywords: copper, preeclampsia, pregnancy, risk, cohort study

Posted Date: September 16th, 2020

DOI: https://doi.org/10.21203/rs.3.rs-70048/v1

License: (c) (i) This work is licensed under a Creative Commons Attribution 4.0 International License. Read Full License 


\section{Abstract \\ Background}

Preeclampsia is a leading cause of maternal and fetal morbidity and mortality. The associations between whole blood copper and pre-eclampsia were controversial. Our study was aimed to investigate the association between whole blood copper concentration and preeclampsia in pregnant woman in China.

\section{Methods}

This retrospective cohort study was conducted between August 1, 2019 to December 31, 2019 in a comprehensive tertiary hospital in Foshan city Guangdong Province, China. We measured copper concentration in maternal whole blood in 12-27 (+6) week of pregnancy, using flame atomic absorption spectrometer. We ascertained preeclampsia diagnosis from electronic medical records system. Covariates included demographic, offspring characteristics, serum biomarkers. Logistic regression was applied to explore the association between the concentration of trace element and preeclampsia.

\section{Results}

A total of 2134 participants were included, 57 (2.67\%) women developed preeclampsia. In the multivariate regression models, per1 SD increment in copper was associated with $28 \%$ lower risk of preeclampsia (OR $=0.72,95 \% \mathrm{Cl}: 0.54-0.95)$. After Propensity-Score Matching with similar age at delivery and prepregnancy BMI,per1 SD increment in copper was associated with $28 \%$ lower risk of preeclampsia $(\mathrm{OR}=0.70,95 \%$ $\mathrm{Cl}: 0.51-0.97)$. We observed some extent evidence of a dose-response trend for $\mathrm{Cu}(\mathrm{P}$ for trend $=0.0321)$ quintiles. And the result was sustained in mild and severe preeclampsia.

\section{Conclusions}

women with higher blood concentration of copper may associated with lower preeclampsia. More well designed studies are needed for the interpretation of these findings.

\section{Background}

Preeclampsia (PE) is a pregnancy-specific complication chiefly characterized by new-onset hypertension and proteinuria after 20 weeks of gestation, and accompanied by signs of damage to other organ systems, such as hemolysis, elevated liver enzymes, and low platelet count.[1, 2] [1, 2]Preeclampsia affects $5 \%$ to $7 \%$ of pregnant women worldwide and it persists as a leading cause of maternal and fetal morbidity and mortality.[3-5] And Hypertensive disorders including preeclampsia of pregnancy are the direct cause of death of about 30000 women annually [6],or approximately $14 \%$ of maternal death[7],most of which occur in low-income countries and have higher maternal mortality rates[8]. 
Strategies to prevent preeclampsia have been studied extensively [9], but only low-dose aspirin treatment may be effective in preventing preeclampsia in high-risk women.[10] Timely delivery of the fetus and placenta still remains the only definitive treatment. However, unfortunately, preeclampsia can persist after delivery and, in some cases, can develop de novo in the postpartum period.[11] Beside, there is accumulating evidence that preeclampsia and eclampsia predisposes to long-term cardiovascular risk.[12, 13]

The etiology of preeclampsia remains ambiguous, albeit, reports that implicated placental defects and oxidative stress early during pregnancy in affected pregnancies. [14]Therefore, identifying modifiable risk factors for preeclampsia is an important priority for reducing morbidity and maternal mortality from preeclampsia.

Copper is an essential trace element, which is a co-factor of antioxidant enzymes, thus appropriate copper is necessary for health and reducing the risk of PE. Many studies attempted to explore the relationships between copper level in pregnant women and PE, but the results varied greatly. Some studies found significantly lower levels of copper in PE patients than the control group.[15-17] However, Some studies report significantly higher levels of copper in PE patients.[18, 19] Meanwhile, some studies find no associations.[20]

Furthermore, to our knowledge, little information is available in the association between copper level during early or mid-term pregnancy and preeclampsia and separately by its subtype. Therefore, research on copper level during early or mid-term pregnancy and preeclampsia is of paramount importance for clinician. In light of these literature gaps, we examined the associations of copper level with pre-eclampsia in women from the China Cohort, using concentrations measured in maternal whole blood in 12-27 (+6) week of pregnancy. We hypothesized that higher copper concentration are associated with lower risk of preeclampsia after appropriate adjustment.

\section{Methods}

\section{Study design, Setting and Participants}

This was a retrospective pregnant women cohort study, studying association of copper level with preeclampsia. The study was conducted in obstetrics department of Foshan Chancheng Central Hospital, Foshan city Guangdong province, China, which obtain the Joint Commission International (JCl) Hospital Accreditation 6th ed. Pregnant women with induced labour, fetal death in uterus, serious birth defects, age at delivery Less than 18 years or more than 42 years were not included in the cohort study.

The population of this study was consecutive participants, which pregnancy registered, checked up and delivered in our hospital among on August 1, 2019 to November 30, 2019. The Hospital Ethics Committee approved this study and waived informed consent because data were unidentified. The study protocols were registered in Chinese Clinical Trial Registry (Registration number: ChiCTR2000029643).All reporting 
followed the Strengthening the Reporting of Observational Studies in Epidemiology (STROBE) guidelines. [21]

2512 women were enrolled in the study. 335 were excluded for the following reasons: 281 had missing information on all four trace element, 5 had chronic hypertension prior to pregnancy, 3 had T2DM prior to pregnancy,20 had twin pregnancy, 1 had $B M I$ missing, 19 had $B M I \geq 30,1$ age $<18,5$ age $>42.2177$ participants were remained quantity. We excluded the extreme value of copper $\leq 1 \%(9.32-13.08, n=22)$ and $>99 \%(21.13-25.98, n=21)$.A total of 2134 participants were included in the final analysis(Figure 1).

\section{Data Collection}

We extracted socio-demographic characteristics and delivery from electronic medical records system. Information on prepregnancy height and weight, smoking and drinking history,education level, past medical history, last menstrual period, parity history, method of conception were gathered by the physicians at the first visit for pregnancy registered. And the first visit for pregnancy registered usually opens at 8-12weeks of gestation in this city. In Guangdong province, China, the typical schedule of routine antenatal visits are at weeks $8-12$,week 16, week 20, week 24, week 28 and thereafter every second week until birth.

Prepregnancy height and weight refers to the height and weight at the first visit for pregnancy registered in 8-12weeks of gestation, which self-reported by pregnant women. Prepregnancy body mass index (BMI) was calculated as weight $(\mathrm{kg})$ divided by height squared(m2).Smoking and drinking refer to no smoking and no drinking in pregnancy, which self-reported by pregnant women at admission to the hospital and before delivery. In this study, all women self-reported no smoking and drinking in pregnancy. Education level included middle school or below, high school, college or above. Parity is divided into nulliparous and multiparous. Method of conception included natural conception, assisted reproductive technology (ART) conception. Gestational age (weeks) was calculated from the first day of last menstrual period (LMP) until the date of delivery. Women with irregular menstrual cycles or unsure of their LMP, we based on their first trimester ultrasound examination to corrected gestational age.

\section{Copper sampling and measurement}

Copper concentration were measured in maternal whole blood in 12-27(+6) week of pregnancy, from women declaring themselves to be fasting. In this study, copper concentrations were measured prior to the date of diagnosis pre-eclampsia. Blood samples were collected from the antecubital vein, using heparin anti-coagulation Vacuum blood vessel collection. Whole blood copper concentration were measured by flame atomic absorption spectrometer (BH5100S, BOHUI, Beijing, China) with copper - zinc composite element hollow cathode lamp at $3 \mathrm{~mA}$ current.

Both before and after the detection, we have internal quality control. Related reagents (trace element calibration solution, batch numbe1070719) were provided by BOHUI, Beijing, China. We respectively conducted calibration before and after testing the sample, with two concentrations of the calibration solution. Copper concentration of the calibration solution were $4.6 \mathrm{mg} / \mathrm{L}$ and $1 \mathrm{mg} / \mathrm{L}$, 
respectively.Correlation coefficients for calibration curves of copper were greater than 0.999. All measurement on copper concentration in maternal whole blood were performed in the Center for Clinical laboratory of Foshan Chancheng Central Hospital. The respective reference intervals of copper concentration in our laboratory included were 7.12-21.29umol/L.

\section{Outcomes}

Preeclampsia was the outcome of this study, obtained directly from electronic medical records system. Preeclampsia was defined according to report of the American College of Obstetricians and Gynecologists' Task Force on Hypertension in Pregnancy.[22]Preeclampsia was defined as newly diagnosed hypertension and proteinuria occurring after 20 weeks of gestation. Hypertension was defined as systolic $\geq 140 \mathrm{mmHg}$ or diastolic $\geq 90 \mathrm{mmHg}, 2$ occasions, $4 \mathrm{~h}$ apart in previously normotensive woman. Proteinuria was defined as $\geq 300 \mathrm{mg} / 24$ hour urine collection, or protein/creatinine $\geq 0.3$,or or dipstick reading $=1+$. Severe preeclampsia case were considered if they had at least one of the following symptoms: 1) Systolic blood pressure $\geq 160 \mathrm{mmHg}$ or diastolic $\geq 110 \mathrm{mmHg}, 2$ occasions, $4 \mathrm{~h}$ apart on

bedrest;2)Thrombocytopenia(blood platelet $<100 \times 10^{9} / \mathrm{L}$ );3) Liver function tests $\geq 2 \times$ normal or severe persistent right upper quadrant or epigastric pain;4)Serum creatinine concentration $>1.1 \mathrm{mg} / \mathrm{dL}$ or doubling of creatinine in the absence of other renal disease;5)Pulmonary edema;6)New-onset cerebral or visual symptoms. All other cases were diagnosed mild pre-eclampsia. Early onset and late onset preeclampsia defined as delivery before 34 and $\geq 34$ weeks, respectively. In this study, all cases of preeclampsia occurred after 28 weeks, with 5 cases of early onset and 52 cases of late onset.

\section{Statistical Analysis}

Frequency and percentage were used in categorical variables, such as education level, parity, and method of conception, delivery way. Normally distributed variables are presented as means and standard deviations (SD). Non-normally distributed variables are presented as median and interquartile range (IQR) We compared categorical variables, normally and non-normally distributed variables between Normal and Pre-eclampsia women, used Pearson Chi-square, ANOVA and Kruskal-Wallis Rank sum test. Scatter plot with bar were used to display the median, IQR, and range of four trace element, and Kruskal-Wallis Rank sum test were used to determine differences in their distributions in Normal and Pre-eclampsia women.

We used Logistic regression analyses to estimate odds ratios and $95 \%$ confidence intervals (Cls) for preeclampsia in relation to trace element, unadjusted model and multivariable adjusted model. Copper concentrations were treated as continuous variables scaled to per1 SD increase and also as categorical variables by quintiles to explore potential nonlinear dose-response relationships on preeclampsia. $P$ values for trend were obtained by coding concentration categories as ordinal variables in the regression models. To assess potential confounders, we adjusted for age at delivery (smooth),prepregnancy body mass index(smooth),education level (middle school or below, high school, college or above),parity(nulliparous, multiparous), and method of conception(natural conception, ART conception). We also evaluated subgroup analysis of copper with preeclampsia. Furthermore, age at delivery, prepregnancy BMI, education 
level, parity and method of conception were considered as potential effect measure modifiers. We conducted interaction test of copper with preeclampsia and showed $\mathrm{P}$ values for interaction under multivariable adjusted model.

We did sensitivity analysis to investigate the robustness of the findings in line with missing data. Nearly all clinical factors were similar in 2231 patients with available data on copper and the 281 patients with missing data on copper (Table S1 in the Supplementary Appendix). It shows that the missing data has little effect on the overall research conclusion to some extent. Given the differences in the baseline characteristics between eligible participate in the two groups, propensity-score matching was used to identity a cohort of patients with similar age at delivery and prepregnancy BMI. Matching was performed with the use of a 1:4 matching protocol Without replacement (greedy-matching algorithm), with a caliper width equal to 0.01 of the standard deviation of the logit of the propensity score. The results were compared in the two different samples, which show that the results are relatively robust (Table S2 in the Supplementary Appendix).

Data management and analyses were performed with the statistical software package R (http: //www.Rproject. org, The R Foundation) and Empower Stats (http:// www.empowerstats.com,X\&Y Solutions, Inc. Boston, MA).And 2-sided $P$ values less than 0.05 were defined statistically significant.

\section{Results}

\section{Characteristics of Participants}

Of the 2134 women included in the analysis, $57(2.67 \%)$ developed preeclampsia.

Women with preeclampsia were more likely to have older, higher prepregnancy body mass index and lower natural conception than women without preeclampsia (Table 1). Babies born to preeclampsia mothers were more likely to have shorter gestation, higher abdominal delivery, lower birth weight and length. Copper concentration in different participants shown in Figure 1S in the Supplementary Appendix, indicated that women with preeclampsia had no statistically significantly than normal participants.

\section{Association Between copper and Preeclampsia}

The odds ratios of preeclampsia was 0.78 (95\% Cl: 0.59-1.02) for copper concentration in unadjusted, and the result was sustained after multivariable adjusted logistic regression analyses(Table 2).Per 1 SD (1.81) increment in copper concentration, there was $28 \%(95 \% \mathrm{Cl}$ : $0.54-0.95)$ lower risk in the OR of preeclampsia after multivariable adjustment. Moreover, the odds ratios of mild and severe preeclampsia was 0.81 (95\% Cl: 0.57-1.14), 0.56(95\% Cl:0.34-0.93), respectively(Table 3).

The fourth and fifth quintiles of copper were associated with $0.25(95 \% \mathrm{Cl}: 0.11-0.58)$ and $0.18(95 \% \mathrm{Cl}: 0.07-$ 0.48) times lower risk of preeclampsia after multivariable adjustment, compared with the first quintile, respectively, in somewhat of a dose-dependent manner ( $P$ for trend=0.0338) (Figure 2). 


\section{Subgroup analysis of copper with Preeclampsia}

In subgroup analysis, The odds ratios for preeclampsia in relationship to per 1 SD increment in copper were consistent among subgroup of age at delivery, prepregnancy BMI, education level, parity, method of conception (Figure 3).

\section{Interaction test of copper with Preeclampsia}

Furthermore, all $\mathrm{P}$ values for interaction test on copper with preeclampsia were not statistically significant, suggesting that the association with copper and preeclampsia was not affected by the interaction between age at delivery, prepregnancy BMI, education level, parity, method of conception(Figure 3).

\section{Discussion}

In this cohort of pregnant women with low burden of preeclampsia, higher copper levels (measured in whole blood at 12-27 ( +6$)$ week of pregnancy) were associated with lower preeclampsia risk in a doseresponse fashion. Because the risk factors like age, parity, and Body Mass Index (BMI) are associated with preeclampsia [1,23], we controlled these confounders in this study. And these associations persisted after controlling for potential confounders and were consistent across levels of age at delivery, prepregnancy $\mathrm{BMI}$, education level, pregnancy, parity, abortion and method of conception.

In recent years, many studies had been performed to evaluate the relationship between blood copper level and PE. Our study founds were consistent with the results of earlier similar studies.[24, 25] Keshavarz $P$ [26]reported in their case-control study that compared with healthy pregnant women, plasma levels of copper in women with preeclampsia were significantly reduced. Similarly, Acikgoz, S also observed significantly low copper levels in preeclampsia

patients,compared to healthy pregnant women.[27]

Whereas, in contrast, a recently published meta-analysis[28],included nine case-control studies and seven cross-sectional in Asians, reported that the serum copper level was significantly higher in the PE patients [SMD (95\% Cl): $1.05(0.34,1.77), Z=2.88, P$ for $Z=0.004 ; I 2=96.9 \%, P$ for $I 2<0.0001)$ ] as compared to the healthy pregnancy control, similarly to another meta-analysis[29].However, studies in two meta-analysis were case-control studies and cross-sectional, which is not sufficiently powerful to demonstrate a causal relationship. Moreover, confounding factors across studies were different in two meta-analysis, which could affect the observed associations. Therefore, the association with $\mathrm{Cu}$ and preeclampsia is controversial, needed more cohort study.

To our best knowledge, our study is the first cohort study to discuss the association between copper level and PE. Our findings showed that higher copper levels were associated with lower preeclampsia risk, consistent after controlling for potential confounders. A major strength of our study is the level of copper were measured in whole blood at 12-27 (+6) week of pregnancy, prior to the date of diagnosis preeclampsia, which is of great clinical significance to prevent the occurrence of preeclampsia. 
However, our study also has limitations of the current study. First, misclassification of preeclampsia could exist, since the diagnosis was extracted directly from electronic medical records. It is reasonable to consider the misclassification as independent and nondifferential, which would bias the observed association towards the null. Second, because there are only 5 cases of early onset preeclampsia in our cohort, we were unable to distinguish between early onset and late onset preeclampsia, which may differ with respect to pathogenesis and clinical managements[30].Therefore, we cannot specifically discern whether copper level have different associations with early onset and late onset preeclampsia in our study. Third, we excluded people with self-reported chronic hypertension prior to pregnancy, T2DM prior to pregnancy, $\mathrm{BMI} \geq 30$, and twin pregnancy,So our findings do not apply to this population. Fourth, missing data were unavoidable as we did a retrospective study. Considering that the missing data were caused by non-human factors and many were from the same individuals, patients with missing data were not included in the subsequent analysis. The statistical power might be reduced as exclude patients with missing information on copper. There might also be an effect on the findings and increased bias, while the relatively large sample in this study could compensate for this. Additionally, nearly all clinical factors were similar in 2231 patients with available data on copper and the 281 patients with missing data on copper(Table S1 in the Supplementary Appendix).Finally, because our study is observational, we cannot rule out the possibility of residual or unmeasured confounding of the reported associations. Future studies including a larger cohort with standardised data collection is necessary to further validate these results.

\section{Conclusion}

Women with higher blood concentration of copper may associated with lower preeclampsia. More well designed studies are needed for the interpretation of these findings.

\section{Declarations}

\section{Ethical Approval and Consent to participate}

The Hospital Ethics Committee approved this study and waived informed consent because data were unidentified (approval number: CYIRB2020001PJ20200316).

\section{Consent for publication}

Not applicable.

\section{Availability of supporting data}

The data, analytic methods, and study materials that support the findings of this study available from $\mathrm{Dr}$ Huan Ying Xu (843857263@qq.com) on reasonable request. 


\section{Competing interests}

The authors declare that they have no competing interests.

\section{Funding}

No specific funding was obtained to this study.

\section{Authors' contributions}

H.Y.X. and S.Z.W. conceptualized and designed the study; Q.L.Z., Yu Chen (Y.C.), M.H.T., M.M.Z. and Q.X.O. collected the data or contributed to data analysis; H.Y.X. and Y.C. drafted the initial manuscript; H.Y.X. and Ying Chen (Y.C. ) had primary responsibility for final content, had full access to all the data in the study and takes responsibility for the integrity of the data and the accuracy of the data analysis. All authors read and approved the final manuscript.

\section{Acknowledgements}

The authors thank all of the study participants in this cohort, the Foshan Chancheng Central Hospital Labor and Delivery Nursing Staff.

\section{References}

1. Jeyabalan A. Epidemiology of preeclampsia: impact of obesity. Nutr Rev. 2013;71(Suppl 1):18-25.

2. Ananth CV, Keyes KM, Wapner RJ. Pre-eclampsia rates in the United States, 1980-2010: age-periodcohort analysis. BMJ. 2013;347:f6564.

3. Hogan MC, Foreman KJ, Naghavi M, Ahn SY, Wang M, Makela SM, Lopez AD, Lozano R, Murray CJ. Maternal mortality for 181 countries, 1980-2008: a systematic analysis of progress towards Millennium Development Goal 5. Lancet. 2010;375:1609-23.

4. Abalos E, Cuesta C, Grosso AL, Chou D, Say L. Global and regional estimates of preeclampsia and eclampsia: a systematic review. Eur J Obstet Gynecol Reprod Biol. 2013;170:1-7.

5. Mol BWJ, Roberts CT, Thangaratinam S, Magee LA, de Groot CJM, Hofmeyr GJ. Pre-eclampsia. The Lancet. 2016;387:999-1011.

6. Wang H, Liddell CA, Coates MM, Mooney MD, Levitz CE, Schumacher AE, Apfel H, lannarone M, Phillips B, Lofgren KT, et al. Global, regional, and national levels of neonatal, infant, and under-5 mortality during 1990-2013: a systematic analysis for the Global Burden of Disease Study 2013. Lancet. 2014;384:957-79.

7. Say L, Chou D, Gemmill A, Tuncalp O, Moller AB, Daniels J, Gulmezoglu AM, Temmerman M, Alkema L. Global causes of maternal death: a WHO systematic analysis. Lancet Glob Health. 2014;2:e323-33. 
8. Souza JP, Gulmezoglu AM, Vogel J, Carroli G, Lumbiganon P, Qureshi Z, Costa MJ, Fawole B, Mugerwa Y, Nafiou I, et al. Moving beyond essential interventions for reduction of maternal mortality (the WHO Multicountry Survey on Maternal and Newborn Health): a cross-sectional study. Lancet. 2013;381:1747-55.

9. Maric-Bilkan C, Abrahams VM, Arteaga SS, Bourjeily G, Conrad KP, Catov JM, Costantine MM, Cox B, Garovic V, George EM, et al. Research Recommendations From the National Institutes of Health Workshop on Predicting, Preventing, and Treating Preeclampsia. Hypertension. 2019;73:757-66.

10. Rolnik DL, Wright D, Poon LC, O'Gorman N, Syngelaki A, de Paco Matallana C, Akolekar R, Cicero S, Janga D, Singh M, et al. Aspirin versus Placebo in Pregnancies at High Risk for Preterm Preeclampsia. N Engl J Med. 2017;377:613-22.

11. Goel A, Maski MR, Bajracharya S, Wenger JB, Zhang D, Salahuddin S, Shahul SS, Thadhani R, Seely EW, Karumanchi SA, Rana S. Epidemiology and Mechanisms of De Novo and Persistent Hypertension in the Postpartum Period. Circulation. 2015;132:1726-33.

12. Brouwers L, van der Meiden-van Roest AJ, Savelkoul C, Vogelvang TE, Lely AT, Franx A, van Rijn BB. Recurrence of pre-eclampsia and the risk of future hypertension and cardiovascular disease: a systematic review and meta-analysis. BJOG. 2018;125:1642-54.

13. Berends AL, de Groot CJ, Sijbrands EJ, Sie MP, Benneheij SH, Pal R, Heydanus R, Oostra BA, van Duijn $\mathrm{CM}$, Steegers EA. Shared constitutional risks for maternal vascular-related pregnancy complications and future cardiovascular disease. Hypertension. 2008;51:1034-41.

14. Aouache R, Biquard L, Vaiman D, Miralles F. Oxidative Stress in Preeclampsia and Placental Diseases. Int J Mol Sci 2018, 19.

15. Choi R, Sun J, Yoo H, Kim S, Cho YY, Kim HJ, Kim SW, Chung JH, Oh SY, Lee SY: A Prospective Study of Serum Trace Elements in Healthy Korean Pregnant Women. Nutrients 2016, 8.

16. Sarwar MS, Ahmed S, Ullah MS, Kabir H, Rahman GK, Hasnat A, Islam MS. Comparative study of serum zinc, copper, manganese, and iron in preeclamptic pregnant women. Biol Trace Elem Res. 2013;154:14-20.

17. Maduray K, Moodley J, Soobramoney C, Moodley R, Naicker T. Elemental analysis of serum and hair from pre-eclamptic South African women. J Trace Elem Med Biol. 2017;43:180-6.

18. Rafeeinia A, Tabandeh A, Khajeniazi S, Marjani AJ. Serum copper, zinc and lipid peroxidation in pregnant women with preeclampsia in gorgan. Open Biochem J. 2014;8:83-8.

19. Bakacak M, Kilinc M, Serin S, Ercan O, Kostu B, Avci F, Kiran H, Kiran G. Changes in Copper, Zinc, and Malondialdehyde Levels and Superoxide Dismutase Activities in Pre-Eclamptic Pregnancies. Med Sci Monit. 2015;21:2414-20.

20. Elmugabil A, Hamdan HZ, Elsheikh AE, Rayis DA, Adam I, Gasim GI. Serum Calcium, Magnesium, Zinc and Copper Levels in Sudanese Women with Preeclampsia. PLoS One. 2016;11:e0167495.

21. von Elm E, Altman DG, Egger M, Pocock SJ, Gotzsche PC, Vandenbroucke JP, Initiative S. The Strengthening the Reporting of Observational Studies in Epidemiology (STROBE) Statement: guidelines for reporting observational studies. Int J Surg. 2014;12:1495-9. 
22. American College of O. Gynecologists. Task Force on Hypertension in P: Hypertension in pregnancy. Report of the American College of Obstetricians and Gynecologists' Task Force on Hypertension in Pregnancy. Obstet Gynecol 2013, 122:1122-31.

23. Bartsch E, Medcalf KE, Park AL, Ray JG. High Risk of Pre-eclampsia Identification G: Clinical risk factors for preeclampsia determined in early pregnancy: systematic review and meta-analysis of large cohort studies. BMJ. 2016;353:i1753.

24. Ugwuja El, Akubugwo El, Ibiam UA, Obidoa O. Maternal sociodemographic parameters: impact on trace element status and pregnancy outcomes in Nigerian women. J Health Popul Nutr. 2011;29:15662.

25. Kumru S, Aydin S, Simsek M, Sahin K, Yaman M, Ay G. Comparison of serum copper, zinc, calcium, and magnesium levels in preeclamptic and healthy pregnant women. Biol Trace Elem Res. 2003;94:105-12.

26. Keshavarz P, Nobakht MGBF, Mirhafez SR, Nematy M, Azimi-Nezhad M, Afin SA, Esmaily H, Pourali L, Hakak AM, Soukhtanloo M, et al. Alterations in Lipid Profile, Zinc and Copper Levels and Superoxide Dismutase Activities in Normal Pregnancy and Preeclampsia. Am J Med Sci. 2017;353:552-8.

27. Acikgoz S, Harma M, Harma M, Mungan G, Can M, Demirtas S. Comparison of angiotensin-converting enzyme, malonaldehyde, zinc, and copper levels in preeclampsia. Biol Trace Elem Res. 2006;113:1-8.

28. Song X, Li B, Li Z, Wang J, Zhang D. High serum copper level is associated with an increased risk of preeclampsia in Asians: A meta-analysis. Nutr Res. 2017;39:14-24.

29. Fan Y, Kang Y, Zhang M. A meta-analysis of copper level and risk of preeclampsia: evidence from 12 publications. Biosci Rep 2016, 36.

30. Raymond D, Peterson E. A critical review of early-onset and late-onset preeclampsia. Obstet Gynecol Surv. 2011;66:497-506.

\section{Tables}

\section{Table1. Characteristics of Mother-Child Pairs of Participants $(n=2134)$}




\begin{tabular}{|c|c|c|c|}
\hline Characteristics & Normal & Preeclampsia & P-value \\
\hline $\mathrm{N}$ & 2077(97.33\%) & $57(2.67 \%)$ & \\
\hline \multicolumn{4}{|l|}{ Maternal characteristics } \\
\hline Age at delivery, years, Mean $\pm S D$ & $28.95 \pm 4.14$ & $30.28 \pm 4.82$ & 0.078 \\
\hline Prepregnancy BMI $(\mathrm{kg} / \mathrm{m} 2) \llbracket$ Mean $\pm \mathrm{SD}$ & $20.79 \pm 2.81$ & $22.25 \pm 3.12$ & $<0.001$ \\
\hline Education level, N(\%) & & & 0.749 \\
\hline Middle school or below & $303(14.59 \%)$ & $6(10.53 \%)$ & \\
\hline High school & $515(24.80 \%)$ & $15(26.32 \%)$ & \\
\hline College or above & $1259(60.62 \%)$ & $36(63.16 \%)$ & \\
\hline Parity, N(\%) & & & 0.538 \\
\hline Nulliparous & $971(46.75 \%)$ & $29(50.88 \%)$ & \\
\hline Multiparous & $1106(53.25 \%)$ & $28(49.12 \%)$ & \\
\hline Method of conception, N(\%) & & & 0.001 \\
\hline Natural conception & $2035(97.98 \%)$ & $51(89.47 \%)$ & \\
\hline ART conception & $42(2.02 \%)$ & $6(10.53 \%)$ & \\
\hline \multicolumn{4}{|l|}{ Offspring characteristics } \\
\hline Gestational age (weeks) $\llbracket$ Mean $\pm S D$ & $39.20 \pm 1.19$ & $38.11 \pm 1.49$ & $<0.001$ \\
\hline Method of conception, N(\%) & & & $<0.001$ \\
\hline Abdominal delivery & $635(30.57 \%)$ & $46(80.70 \%)$ & \\
\hline Vaginal delivery & $1442(69.43 \%)$ & $11(19.30 \%)$ & \\
\hline Birth weight $(\mathrm{g}) \otimes$ Mean $\pm S D$ & $3224.89 \pm 396.14$ & $2913.68 \pm 556.75$ & $<0.001$ \\
\hline Birth length $(\mathrm{cm}) \llbracket$ Mean $\pm S D$ & $49.57 \pm 1.60$ & $48.37 \pm 2.41$ & $<0.001$ \\
\hline
\end{tabular}

Abbreviations: BMI, body mass index; SD, standard deviation; ART, Assisted reproductive technology.

Table 2.The odds ratios and $95 \% \mathrm{Cl}$ for Preeclampsia in Relationship to Copper 


\begin{tabular}{|c|c|c|c|c|c|c|c|c|}
\hline & \multirow[t]{2}{*}{ Normal (\%) } & \multirow{2}{*}{$\begin{array}{l}\text { Preeclampsia } \\
(\%)\end{array}$} & \multicolumn{2}{|c|}{ Model 1} & \multicolumn{2}{|c|}{ Model 2} & \multicolumn{2}{|c|}{ Model 3} \\
\hline & & & $\begin{array}{l}\text { OR } \\
(95 \% \\
\text { Cl) }\end{array}$ & $\begin{array}{l}\mathrm{P} \\
\text { Value }\end{array}$ & $\begin{array}{l}\text { OR } \\
(95 \% \\
\text { Cl) }\end{array}$ & $\begin{array}{l}\mathrm{P} \\
\text { Value }\end{array}$ & $\begin{array}{l}\text { OR } \\
\text { (95\% } \\
\text { Cl) }\end{array}$ & $\begin{array}{l}\mathrm{P} \\
\text { Value }\end{array}$ \\
\hline $\begin{array}{l}\mathrm{Cu} \\
\text { (umol/L) }\end{array}$ & 2077(97.33\%) & $57(2.67 \%)$ & & & & & & \\
\hline $\begin{array}{l}\text { Per 1 SD } \\
(1.81) \\
\text { increment }\end{array}$ & N.A. & & $\begin{array}{l}0.78 \\
(0.59 \\
1.02)\end{array}$ & 0.0711 & $\begin{array}{l}0.75 \\
(0.57 \\
0.99)^{\prime}\end{array}$ & 0.0434 & $\begin{array}{l}0.72 \\
(0.54 \\
0.95)\end{array}$ & 0.0226 \\
\hline $\begin{array}{l}\text { Quintile } \\
1(13.22- \\
15.97)\end{array}$ & $128(6.16 \%)$ & $10(17.54 \%)$ & Ref. & & Ref. & & Ref. & \\
\hline $\begin{array}{l}\text { Quintile } \\
2(16.00- \\
16.99)\end{array}$ & 397 (19.11\%) & $3(5.26 \%)$ & $\begin{array}{l}0.10 \\
(0.03 \\
0.36)\end{array}$ & 0.0005 & $\begin{array}{l}0.10 \\
(0.03 \\
0.36)\end{array}$ & 0.0005 & $\begin{array}{l}0.09 \\
(0.02 \\
0.34)\end{array}$ & 0.0004 \\
\hline $\begin{array}{l}\text { Quintile } \\
3(17.00- \\
17.98)\end{array}$ & $432(20.80 \%)$ & $20(35.09 \%)$ & $\begin{array}{l}0.59 \\
(0.27 \\
1.30)^{\prime}\end{array}$ & 0.1910 & $\begin{array}{l}0.52 \\
(0.24 \\
1.16)\end{array}$ & 0.1110 & $\begin{array}{l}0.49 \\
(0.22, \\
1.09)\end{array}$ & 0.0798 \\
\hline $\begin{array}{l}\text { Quintile } \\
4(18.00- \\
19.99)\end{array}$ & 671 (32.31\%) & $16(28.07 \%)$ & $\begin{array}{l}0.31 \\
(0.14 \\
0.69)\end{array}$ & 0.0042 & $\begin{array}{l}0.28 \\
(0.12 \\
0.63)\end{array}$ & 0.0022 & $\begin{array}{l}0.25 \\
(0.11 \\
0.58)\end{array}$ & 0.0011 \\
\hline $\begin{array}{l}\text { Quintile } \\
5(20.00- \\
21.13)\end{array}$ & 449 (21.62\%) & 8 (14.04\%) & $\begin{array}{l}0.23 \\
(0.09 \\
0.59)\end{array}$ & 0.0023 & $\begin{array}{l}0.21 \\
(0.08 \\
0.54)\end{array}$ & 0.0013 & $\begin{array}{l}0.18 \\
(0.07 \\
0.48)\end{array}$ & 0.0006 \\
\hline$P$ for tend & N.A. & & 0.0817 & & 0.0554 & & 0.0321 & \\
\hline
\end{tabular}

Abbreviations: N.A. indicates not applicable.

Ref, reference group.

Model 1 was an unadjusted model.

Model 2 was adjusted for age at delivery (smooth), prepregnancy body mass index (smooth) .

Model 3 was adjusted for age at delivery (smooth), prepregnancy body mass index (smooth),education level(middle school or below, high school, college or above),parity(nulliparous, multiparous), and Method of conception(natural conception, ART conception).

Table 3.The odds ratios and 95\% $\mathrm{Cl}$ for Severe and Mild Preeclampsia in Relationship to Copper 


\begin{tabular}{|c|c|c|c|c|c|c|c|}
\hline & \multirow{3}{*}{ Nomal(\%) } & \multicolumn{3}{|c|}{ Severe Preeclampsia } & \multicolumn{3}{|l|}{ Mild Preeclampsia } \\
\hline & & \multirow{2}{*}{$\begin{array}{l}\text { Severe } \\
\text { Preeclampsia(\%) }\end{array}$} & \multicolumn{2}{|c|}{ Model 3} & \multirow{2}{*}{$\begin{array}{l}\text { Mild } \\
\text { Preeclampsia(\%) }\end{array}$} & \multicolumn{2}{|c|}{ Model 3} \\
\hline & & & $\begin{array}{l}\text { OR } \\
(95 \% \\
\text { Cl) }\end{array}$ & $\begin{array}{l}\mathrm{P} \\
\text { Value }\end{array}$ & & $\begin{array}{l}\text { OR } \\
(95 \% \\
\text { Cl) }\end{array}$ & $\begin{array}{l}\mathrm{P} \\
\text { Value }\end{array}$ \\
\hline $\begin{array}{l}\text { Per 1 SD } \\
(1.81) \\
\text { increment }\end{array}$ & 2077 & 20 & $\begin{array}{l}0.56 \\
(0.34 \\
0.93)\end{array}$ & 0.0239 & 37 & $\begin{array}{l}0.81 \\
(0.57 \\
1.14)\end{array}$ & 0.2285 \\
\hline $\begin{array}{l}\text { Quintile } \\
1(13.22- \\
15.97)\end{array}$ & $\begin{array}{l}128 \\
(6.16 \%)\end{array}$ & $5(25.00 \%)$ & Ref. & & $5(13.51 \%)$ & Ref. & \\
\hline $\begin{array}{l}\text { Quintile } \\
2(16.00- \\
16.99)\end{array}$ & $\begin{array}{l}397 \\
(19.11 \%)\end{array}$ & $1(5.00 \%)$ & $\begin{array}{l}0.06 \\
(0.01 \\
0.52)\end{array}$ & 0.0108 & $2(5.41 \%)$ & $\begin{array}{l}0.12 \\
(0.02 \\
0.65)\end{array}$ & 0.0135 \\
\hline $\begin{array}{l}\text { Quintile } \\
3(17.00- \\
17.98)\end{array}$ & $\begin{array}{l}432 \\
(20.80 \%)\end{array}$ & $8(40.00 \%)$ & $\begin{array}{l}0.39 \\
(0.12 \\
1.24)\end{array}$ & 0.1101 & $12(32.43 \%)$ & $\begin{array}{l}0.60 \\
(0.21 \\
1.78)\end{array}$ & 0.3597 \\
\hline $\begin{array}{l}\text { Quintile } \\
4(18.00- \\
19.99)\end{array}$ & $\begin{array}{l}671 \\
(32.31 \%)\end{array}$ & $4(20.00 \%)$ & $\begin{array}{l}0.13 \\
(0.03 \\
0.49)\end{array}$ & 0.0028 & $12(32.43 \%)$ & $\begin{array}{l}0.37 \\
(0.13 \\
1.10)\end{array}$ & 0.075 \\
\hline $\begin{array}{l}\text { Quintile } \\
5(20.00- \\
21.13)\end{array}$ & $\begin{array}{l}449 \\
(21.62 \%)\end{array}$ & $2(10.00 \%)$ & $\begin{array}{l}0.09 \\
(0.02 \\
0.47)\end{array}$ & 0.0046 & $6(16.22 \%)$ & $\begin{array}{l}0.27 \\
(0.08 \\
0.94)\end{array}$ & 0.0393 \\
\hline
\end{tabular}

Model was adjusted for age at delivery (smooth),prepregnancy body mass index (smooth), education level (middle school or below, high school, college or above), parity (nulliparous, multiparous), and Method of conception(natural conception, ART conception).

\section{Figures}


$\mathbf{N}=\mathbf{2 5 1 2}$ participants were eligible for this study

335 were excluded:

Missing information on copper, $\mathrm{n}=281$

Chronic hypertension prior to pregnancy, $n=4$

T2DM prior to pregnancy, $n=3$

Twin pregnancy, $\mathrm{n}=21$

BMI missing, $n=1$

$\mathrm{BMI} \geq 30, \mathrm{n}=19$

Age $<18, n=1$

Age $>42, n=5$

$\mathbf{N}=\mathbf{2 1 7 7}$ remaining quantity

2120 normal pregnant women, 57 women developed preeclampsia

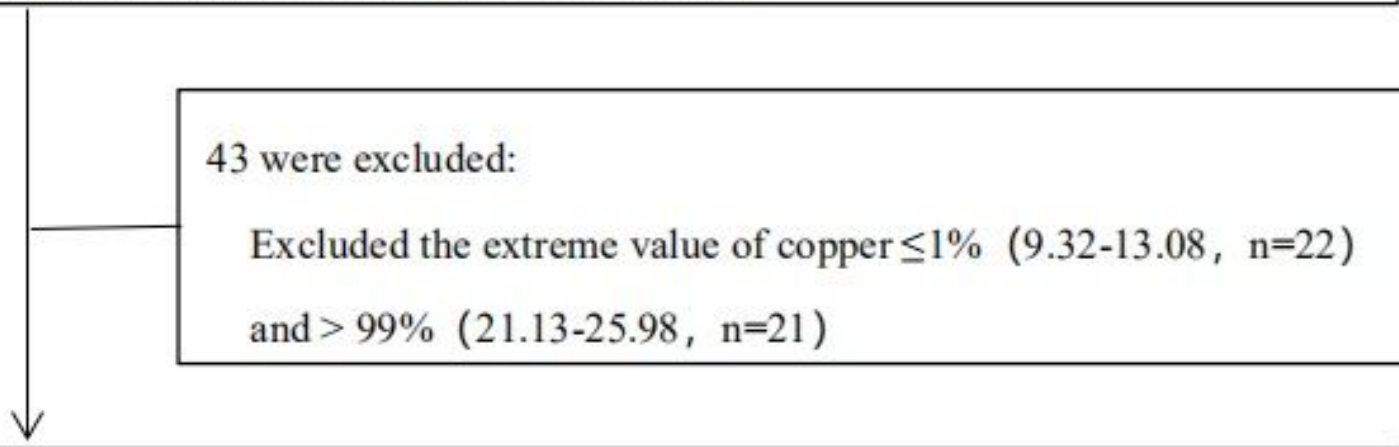

$\mathbf{N}=\mathbf{2 1 3 4}$ remaining quantity

2077 normal pregnant women, 57 women developed preeclampsia

\section{Figure 1}

Flow chart of participant selection 


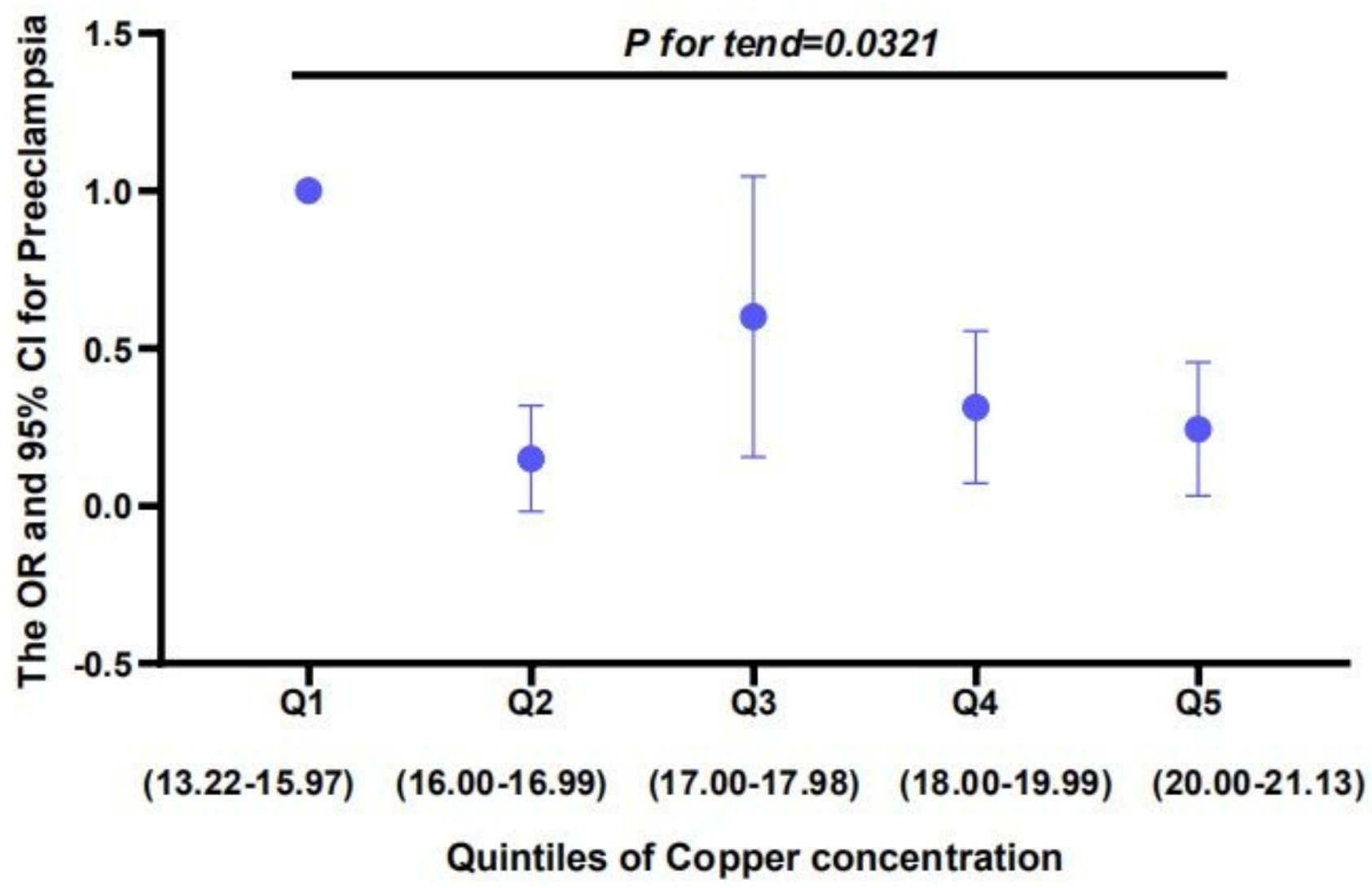

Figure 2

The odds ratios and $95 \% \mathrm{Cl}$ for preeclampsia in relationship to quintiles of copper. Models adjusted for adjusted for age at delivery (smooth),prepregnancy body mass index (smooth), education level (middle school or below, high school, college or above), parity (nulliparous, multiparous), and Method of conception(natural conception, ART conception). 


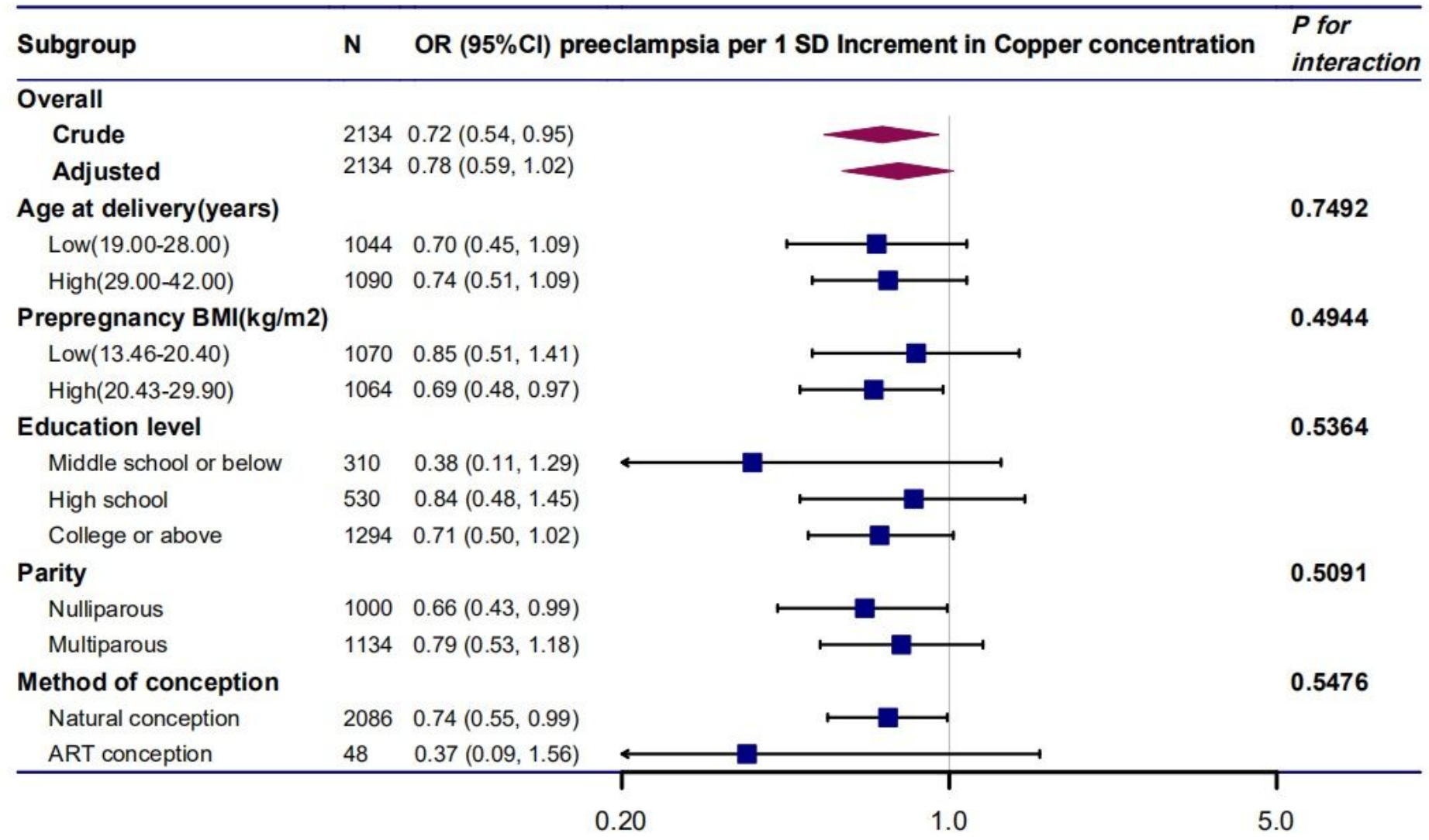

\section{Figure 3}

Subgroup analysis of association of per 1 SD Increment of Copper Concentrations with preeclampsia, by potential effect measure modifiers.

\section{Supplementary Files}

This is a list of supplementary files associated with this preprint. Click to download.

- SupportingFiles.rar

- SupplementaryAppendix.doc 